\title{
On network suppression of multidrug-resistant pathogen spread
}

\author{
Monika Piotrowska ${ }^{1}$, Aleksandra Puchalska², and Konrad Sakowski ${ }^{2}$ \\ ${ }^{1}$ University of Warsaw \\ ${ }^{2}$ University of Warsaw Faculty of Mathematics Informatics and Mechanics
}

October 17, 2021

\begin{abstract}
In the paper we present a system of SIS type equations coupled by impulses at fixed times that describe the transfer of patients in the healthcare system represented by a graph of healthcare facilities and corresponding communities. The first aim for this considerations is to provide rigorous mathematical analysis of a general theoretical model, which is then used to model transmission of hospital acquired multidrug-resistant bacteria infections based on real patient hospital records provided by German insurance company - AOK Lower Saxony. Starting from the existence and the asymptotic behaviour, together with specification of parameter $R_{0}$, we propose sufficient conditions guaranteeing network suppression of infection. Furthermore, conditions derived analytically and proposed numerical procedure are used to indicate healthcare facilities that are most prone to the high prevalence bacteria spread in the healthcare system and to ensure the stability of disease-free steady state of the system.
\end{abstract}

\section{Hosted file}

article.pdf available at https://authorea.com/users/441505/articles/541988-on-networksuppression-of-multidrug-resistant-pathogen-spread 
H-nodes
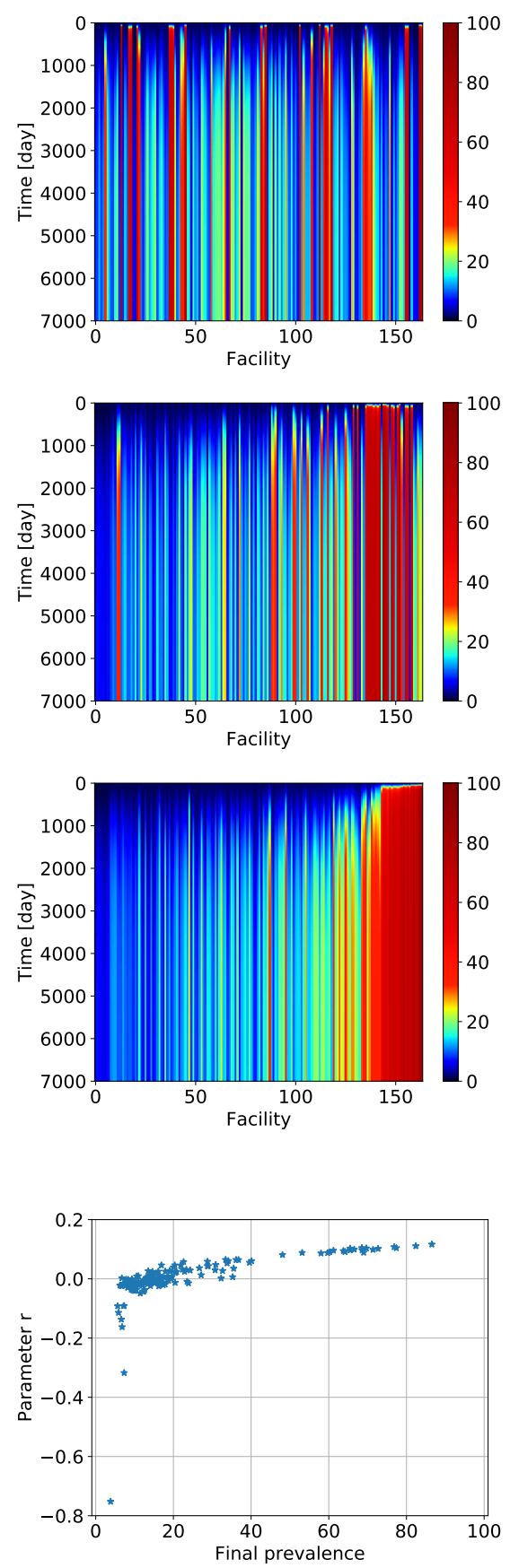

C-nodes
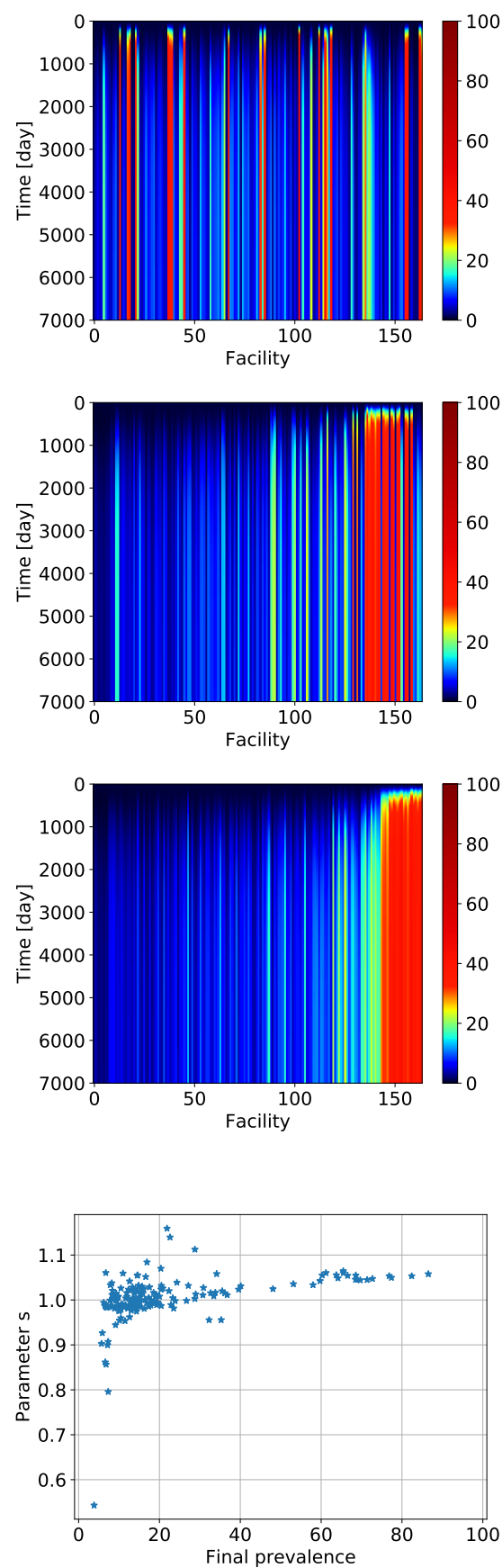

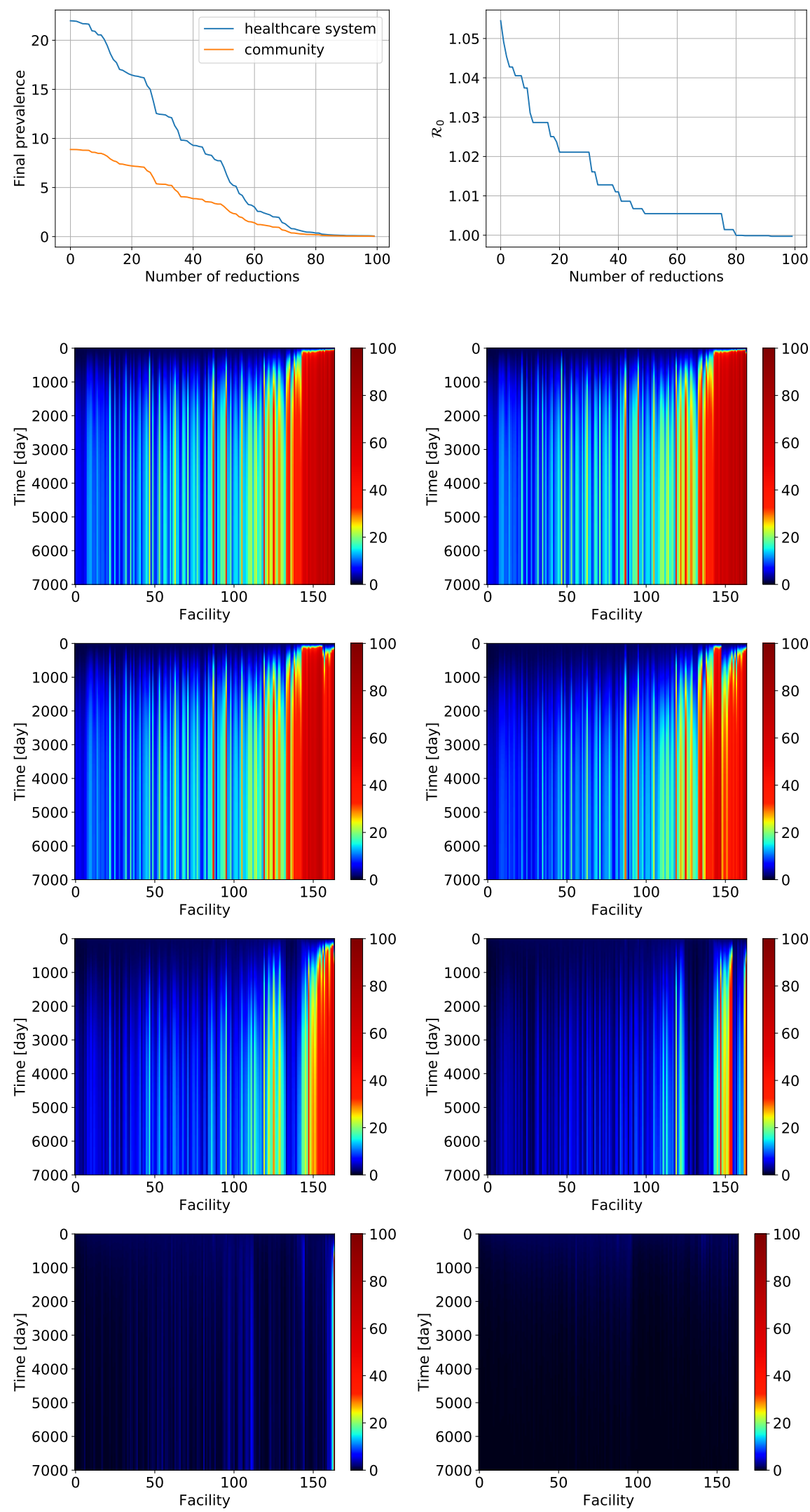

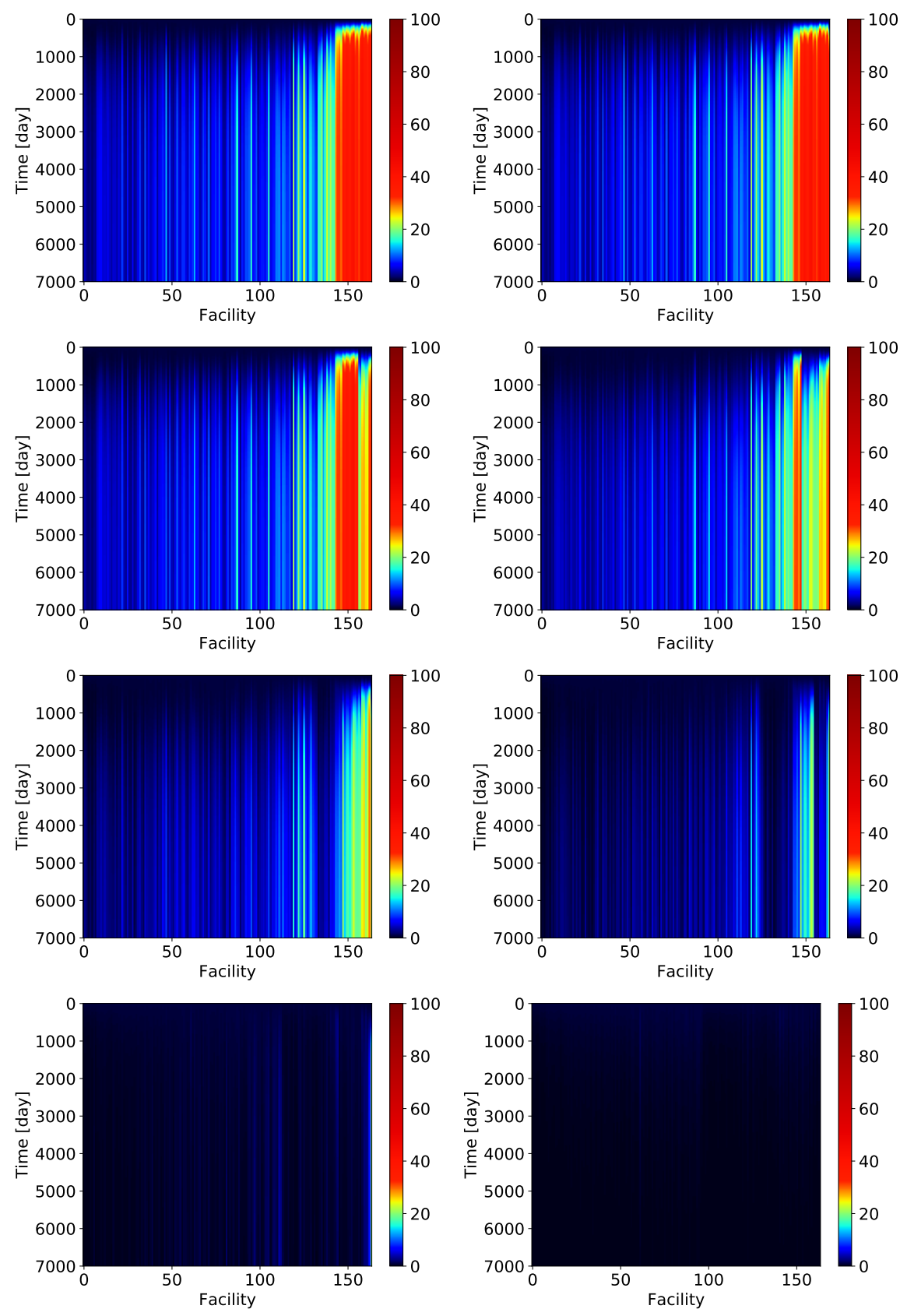


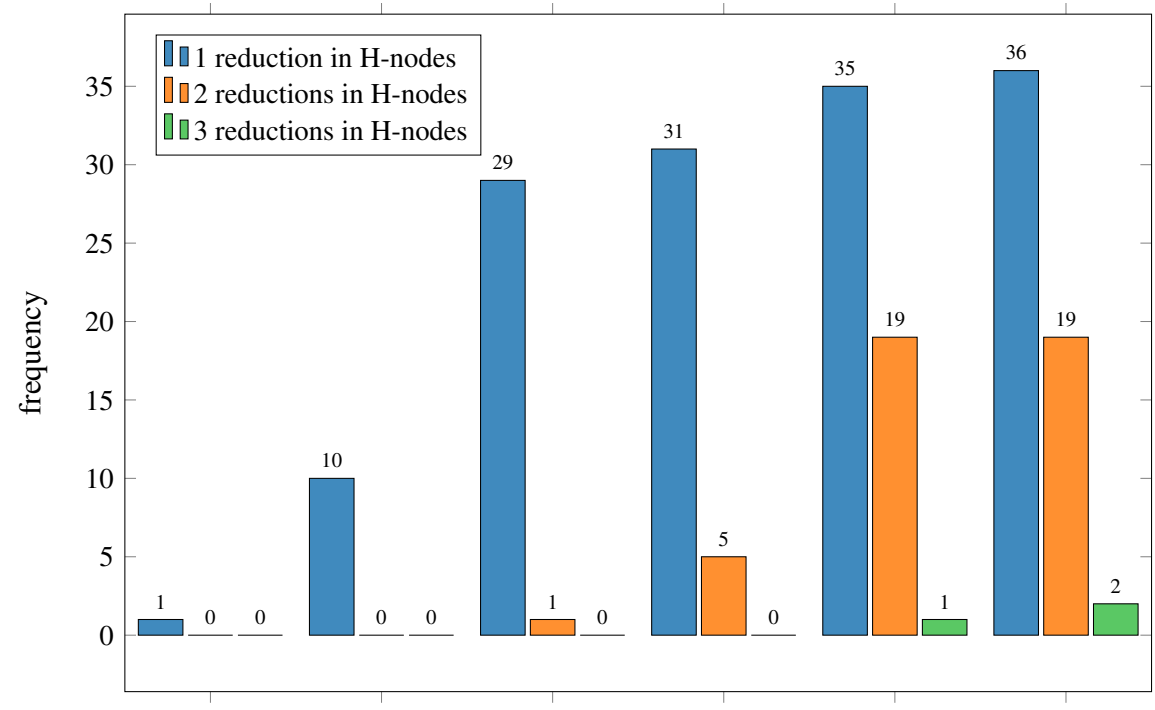

iteration $1 \quad$ iteration $10 \quad$ iteration $31 \quad$ iteration $41 \quad$ iteration $76 \quad$ iteration 80 

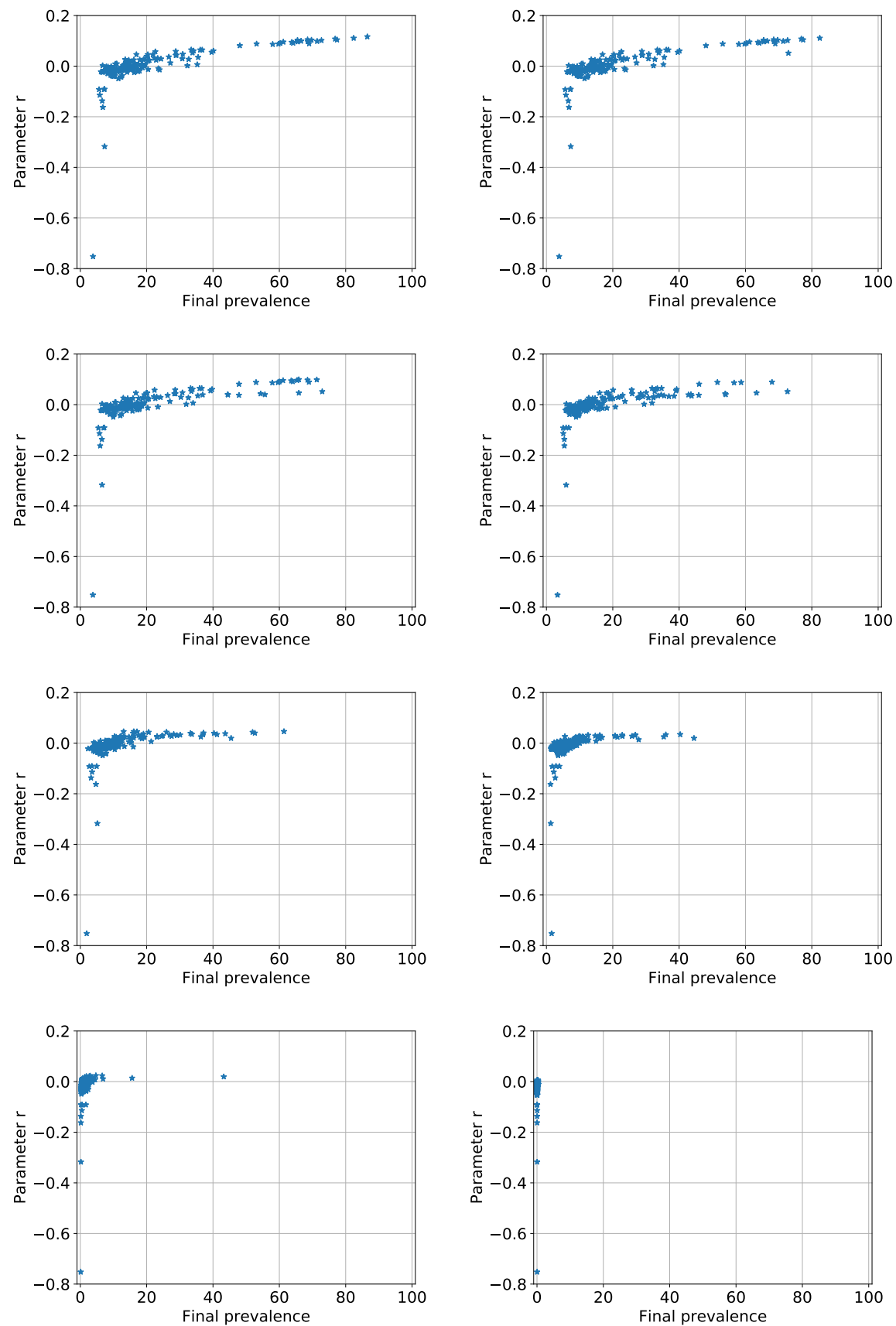